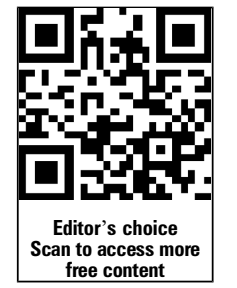

free content
${ }^{1}$ Akdeniz University Medical Faculty, Department of Emergency Medicine, Antalya, Turkey

${ }^{2}$ Pamukkale University Medical Faculty, Department of Emergency Medicine, Denizli, Turkey

${ }^{3}$ Etimesgut Military Hospital, Department of Family Medicine, Ankara, Turkey

Correspondence to Professor Mustafa Serinken, Pamukkale University Medical Faculty, Department Emergency Medicine, Denizli, 20020, Turkey; mserinken@hotmail.com

Received 5 July 2012 Revised 6 November 2012 Accepted 6 January 2013 Published Online First 13 February 2013

\section{SLinked}

- http://dx.doi.org/10.1136/ emermed-2013-203044

- http://dx.doi.org/10.1136/ emermed-2014-203566

To cite: Eken $C$ Serinken $M$, Elicabuk $H$, et al. Emerg Med J 2014;31:177-181.

\title{
Intravenous paracetamol versus dexketoprofen versus morphine in acute mechanical low back pain in the emergency department: a randomised double-blind controlled trial
}

\author{
Cenker Eken, ${ }^{1}$ Mustafa Serinken, ${ }^{2}$ Hayri Elicabuk, ${ }^{2}$ Emrah Uyanik, ${ }^{2}$ Muhammed Erdal ${ }^{3}$
}

\begin{abstract}
Study objective The objective of this study was to determine the analgesic efficacy and safety of intravenous, single-dose paracetamol versus dexketoprofen versus morphine in patients presenting with mechanical low back pain (LBP) to the emergency department (ED).

Methods This randomised double-blind study compared the efficacy of intravenous $1 \mathrm{gm}$ paracetamol, $50 \mathrm{mg}$ dexketoprofen and $0.1 \mathrm{mg} / \mathrm{kg}$ morphine in patients with acute mechanical LBP. Visual analogue scale (VAS) was used for pain measurement at baseline, after 15 and after $30 \mathrm{~min}$.

Results A total of 874 patients were eligible for the study, and 137 of them were included in the final analysis: 46 patients from the paracetamol group, 46 patients in the dexketoprofen group and 45 patients in the morphine group. The mean age of study subjects was $31.5 \pm 9.5$ years, and $60.6 \%(n=83)$ of them were men. The median reduction in VAS score at the 30th minute for the paracetamol group was $65 \mathrm{~mm}(95 \% \mathrm{Cl}$ 58 to 72$), 67 \mathrm{~mm}(95 \% \mathrm{Cl} 60$ to 73$)$ for the morphine group and $58 \mathrm{~mm}(95 \% \mathrm{Cl} 50$ to 64$)$ for the dexketoprophen group. Although morphine was not superior to paracetamol at 30 min (difference: $3.8 \pm 4.9$ (95\% Cl -6 to 14), the difference between morphine and dexketoprofen in reducing pain was $11.2 \pm 4.7$ (95\% $\mathrm{Cl} 2$ to 21). At least one adverse effect occurred in $8.7 \%(n=4)$ of the cases in the paracetamol group, $15.5 \%(n=7)$ of the morphine group, and $8.7 \%(n=4)$ of the dexketoprophen group $(p=0.482)$.

Conclusions Intravenous paracetamol, dexketoprofen and morphine are not superior to each other for the treatment of mechanical LBP in ED.
\end{abstract}

\section{INTRODUCTION}

Acute mechanical low back pain (LBP) is one of the most common complaints at the emergency department (ED), accounting for more than six million cases in the USA. Two-thirds of adults experience mechanical LBP at some points in their lives. ${ }^{1}$

Therapy for acute LBP aims to relieve pain and improve function. Non-steroidal anti-inflammatory drugs (NSAIDs) and opioids can be used for acute LBP in the ED. Opioids are effective analgesics that act rapidly. However, opioids have side effects, such as hypotension, nausea, vomiting and dizziness, which are frequently seen during their use. ${ }^{23}$

Parenteral NSAIDs have emerged as alternative drugs to opioids for any kind of pain in the ED in recent years. A Cochrane meta-analysis showed that
NSAIDs are not less effective than opioids in ceasing renal colic with less rescue medication and side effects. ${ }^{4}$ Dexketoprofen trometamol, a nonselective NSAID, is an active enantiomer of racemic ketoprofen, which is also more lipophilic than ketoprofen. The advantages of dexketoprofen to ketoprofen are more rapid acting, more potent and with less gastrointestinal side effects. ${ }^{5}$

Intravenous paracetamol is a new and safe alternative to NSAIDs and opioids. Although there is evidence that intravenous paracetamol is effective for postoperative pain, ${ }^{67}$ there are very few studies that have investigated the usage of intravenous paracetamol in the ED. ${ }^{8-10}$ The efficacy of intravenous paracetamol, and whether it is a suitable alternative to opioids and NSAIDs, is still a subject of research. ${ }^{9}$

The objective of the present study was to compare the analgesic effects of intravenous paracetamol, intravenous dexketoprofen and intravenous morphine in patients presenting with acute mechanical LBP to the ED.

\section{MATERIAL AND METHODS}

\section{Study design}

Three treatment arms, intravenous paracetamol, intravenous dexketoprofen and intravenous morphine were compared in this single-center, prospective, randomised, double-blind, controlled clinical trial. This study was planned as a superiority trial.

\section{Setting}

The study was conducted in the ED of a tertiary care university hospital with an annual census of approximately 44000 adult visits between February 2011 and July 2011.

All patients provided written informed consent, and the local ethics committee approved the study. The ID for clinicaltrials.gov was NCT01422291.

\section{Selection of participants}

Adults (aged 18-55) with moderate or severe acute mechanical LBP according to the 4-point verbal rating scale (VRS) were accepted as eligible for the study. Acute LBP was accepted as having pain that started over the last week. Exclusion criteria included patients taking analgesic medications in the last $6 \mathrm{~h}$, pregnancy, those who denied to give informed consent, peritoneal irritation signs, haemodynamic instability, renal transplantation, renal, liver, cardiac or pulmonary failure, malignancy, pain indicating sciatalgia, positive Straight Leg Raise Test, neurological deficit, 
known allergy to study drugs, probable renal or biliar colic and illiterate patients.

Study patients were included into the study consecutively $24 \mathrm{~h}$ a day and 7 days a week. The eligibility of patients was confirmed by the senior emergency medicine resident.

\section{Interventions}

Study patients were randomised in a 1:1:1 ratio to receive a single intravenous dose of paracetamol (Perfalgan, Bristol Myers, France) (1 g in $100 \mathrm{ml}$ normal saline solution), morphine $(0.1 \mathrm{mg} / \mathrm{kg}$ in $100 \mathrm{ml}$ normal saline) or dexketoprofen (50 mg in $100 \mathrm{ml}$ normal saline solution). Eight computerised randomisation blocks were prepared and scheduled by a person blinded to the study. Treatment allocation assignments and numbers were contained in sealed envelopes. Study drugs were identical in colour and appearance. They were prepared by a study nurse and administered by a second nurse blinded to the study. Patients with inadequate pain relief after $30 \mathrm{~min}$ received $1 \mathrm{mcg} / \mathrm{kg}$ fentanyl as a rescue drug.

\section{Methods of measurement}

Measurement of pain intensity was performed by a $100 \mathrm{~mm}$ visual analogue scale (VAS) (bounded by 'no pain' and 'the worst pain') and a 4-point VRS (no pain, mild pain, moderate pain and severe pain) before the study drug administration and at the 15 th and 30th minutes. Patients were blinded to the previous VAS scores. The need for the rescue drug at the 30th minute was also recorded. Adverse events, such as nausea, vomiting, allergic reaction, dizziness or vertigo were recorded in the study form.

\section{Outcome measures}

The primary outcome measures were the change in VAS and VRS at the 15 th and 30 th minutes. Secondary outcome measures were the need for the rescue drug and presence of adverse events.

\section{Statistical analysis}

Study data was analysed with MedCalc 11.0.4 and SPSS 19.0 and CI analysis software. The numeric data was presented as the mean $\pm S D$, ordinal data as the median interquartile range (IQR) and categorical data as rate. Paired group comparisons for three or more groups were performed by related measures of analysis of variance (ANOVA) (if the data was distributed normally) or Friedman test. Two group comparisons for paired data were performed by Wilcoxon test or paired t test (if the data was distributed normally). Three-group comparison for non-paired numeric data was performed by both one-way ANOVA (for the normally distributed data) or Kruskal-Wallis test and $\chi^{2}$ test for categorical data. Normality analysis was performed by the Kolmogorov-Smirnov test. All the findings were presented by using a 95\% CI (95\% CI). For a $19 \mathrm{~mm}$ SD and clinical significance of $20 \mathrm{~mm}$, a minimum of 24 patients would be required for each group with 95\% power. The statistical analysis was planned to be performed according to the intention-to-treat analysis. All hypotheses were constructed as two-tailed and an $\alpha$ critical value of 0.05 was accepted as significant.

\section{RESULTS}

A total of 874 patients were eligible for the study, and 737 of them were excluded due to a variety of reasons (figure 1). A total of 137 patients were randomised for the study; 46 patients for the paracetamol group, 46 patients for the dexketoprofen group and 45 patients for the morphine group. Although there was no patient completely excluded from the study after treatment allocation, 30 min VAS measurements could not be performed in four patients despite obtaining the 15 min VAS scores. One patient had an allergic reaction in the paracetamol group, one patient voluntarily left the ED in the dexketoprofen group, and two patients had hypotension and sedation in the morphine group (figure 1). These patients were included in the statistical analysis.

The mean age of study subjects was $31.5 \pm 9.5$ years and $60.6 \%(n=83)$ of them were men. No statistical difference was detected between study groups according to age and gender.

\section{MAIN RESULTS}

Every drug effectively reduced pain at the end of the $30 \mathrm{~min}$. The median reduction in VAS score at $30 \mathrm{~min}$ for the paracetamol group was $65 \mathrm{~mm}(58-72), 67 \mathrm{~mm} \mathrm{(60-73)}$ for the morphine group and $58 \mathrm{~mm}$ (50-64) for the dexketoprofen. VRS scores were also consistent with VAS scores at the 30th minute for all three groups (table 1). Although morphine was not superior to paracetamol at $30 \mathrm{~min}(3.8 \pm 4.9 \mathrm{~mm}(-6$ to -14$))$, the difference between the morphine and dexketoprofen was 11.2 $\pm 4.7 \mathrm{~mm}(2-21)$ (table 2 and figure 2).

A total of 17 patients required the rescue drug at the end of the study. The rescue drug was required by $8(17.4 \%)$ patients in the paracetamol group, 2 patients $(4.4 \%)$ in the morphine group and 7 patients $(15.2 \%)$ in the dexketoprofen group $(p=0.135)$.

At least one adverse effect occurred in $8.7 \%(n=4)$ of subjects in the paracetamol group, $15.5 \%(n=7)$ of the morphine group, and $8.7 \%(n=4)$ of the dexketoprofen group $(\mathrm{p}=0.482)$ (table 3).

\section{DISCUSSION}

Some practical guidelines were recommend for staying active: brief education, paracetamol, NSAIDs, spinal manipulation therapy, muscle relaxants (as second-line drugs only, because of side effects), and weak opioids (in selected cases). ${ }^{11}{ }^{12}$ Most of them usually recommend paracetamol and NSAIDs as initial drugs. COX-2 inhibitors, muscle relaxants and opioids have not shown to be more effective than NSAIDs for acute LBP according to these guidelines. ${ }^{13-15}$

Oral acetaminophen is one of the most widely used agents for acute pain relief, but historically, poor solubility and stability of this agent in aqueous solution prevented its use in an intravenous form. A stable formulation of intravenous acetaminophen (ie, paracetamol) is commercially available in Europe with Phase III trials pending in the USA and Canada. ${ }^{16}$ In the USA, acetaminophen has so far only been available as an oral or rectal formulation. On 2 November 2010, the Food and Drug Administration approved an intravenous form of acetaminophen for relieving pain and fever after surgery (Ofirmev, Cadence Pharmaceuticals, San Diego, California, USA). ${ }^{17}$

Intravenous paracetamol is a safe and effective drug for acute pain management although its mechanism of action is still a controversial issue. Although most studies are interested in postoperative pain, intravenous paracetamol has been found to be as effective as opioids. ${ }^{6}$ Two recent studies by Bektas et al ${ }^{8}$ and Serinken et al ${ }^{10}$ reported that morphine is not superior to paracetamol in patients who have presented with renal colic to the ED.

Although NSAIDs are recommended in most international guidelines for the management of LBP, recent systematic reviews have concluded that NSAIDs produce only relatively small benefits in people with LBP and may not be more effective than the simple analgesic paracetamol. NSAIDs are also associated with serious adverse reactions compared with paracetamol (relative 


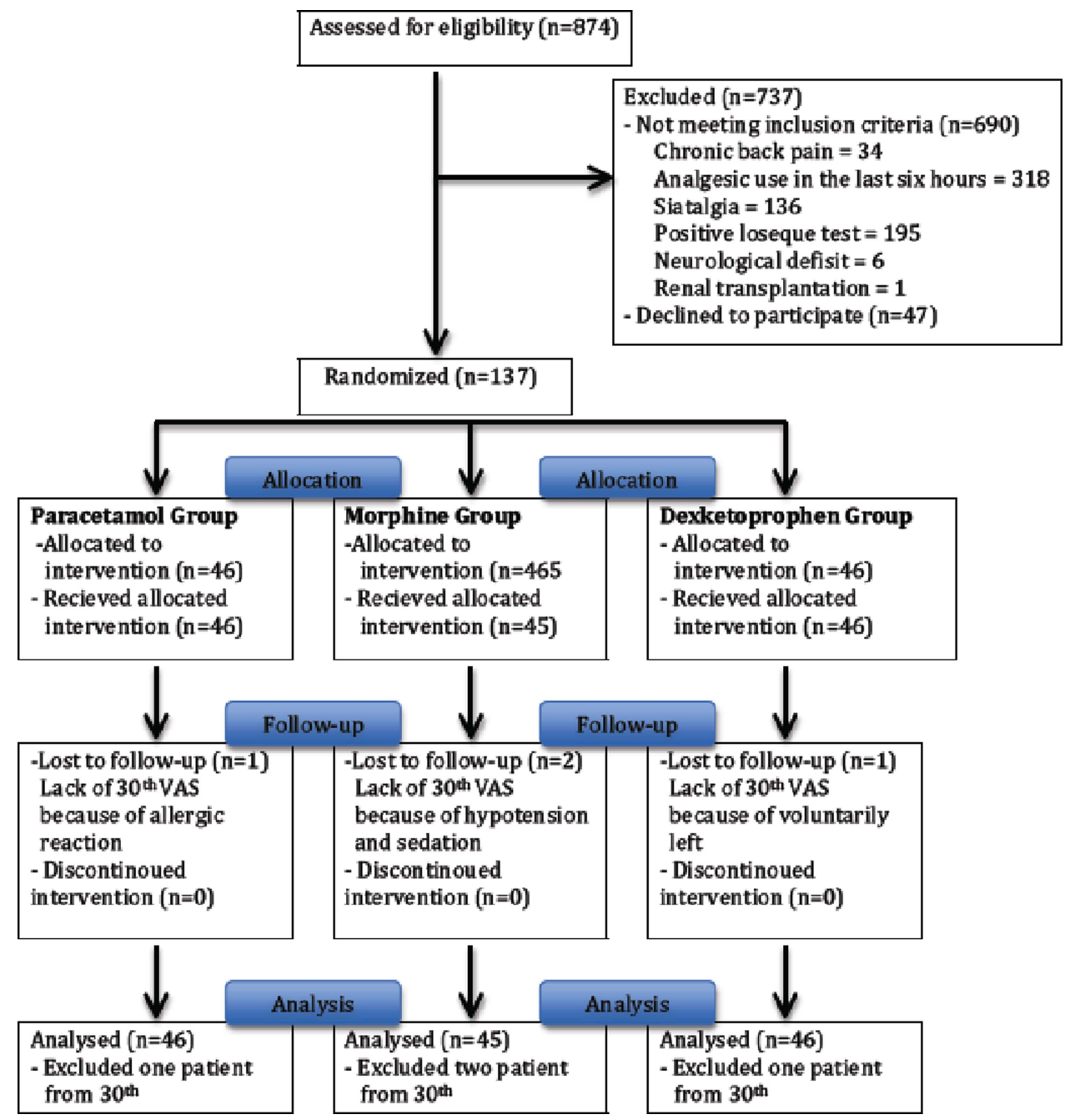

Figure 1 Patient flow chart.

risk (RR) 1.76 ; 95\% CI 1.12 to 2.76 ) including renal, cardiovascular and gastrointestinal conditions which limit their use to patients who would likely benefit from its use. ${ }^{17}$
There is only one study regarding the use of paranteral analgesics for LBP in the ED, which is musculoskeletal in origin. Veenema $e t a l^{3}$ compared ketorolac with meperidine and found

Table 1 Pain measurements at 0, 15th and 30th minutes

\begin{tabular}{llll}
\hline Variables & Paracetamol group $\mathrm{n}=\mathbf{4 6}$ & Morphine group $\mathbf{n}=\mathbf{4 5}$ & Dexketoprophen group, $\mathrm{n}=\mathbf{4 6}$ \\
\hline VAS score, mean \pm SD, median (IQR) & & & \\
Baseline & $82.6 \pm 12.6$ & $81.4 \pm 12.3$ & $83.5 \pm 10.8$ \\
& $80(75-91)$ & $80(75-90)$ & $80(78-90)$ \\
15th minute & $50.6 \pm 25.3$ & $38 \pm 24.5$ & $50.5 \pm 18$ \\
& $50(40-70)$ & $40(17.5-56.25)$ & $27.6 \pm 20.4$ \\
30th minute & $19 \pm 22.4$ & $15.5 \pm 16$ & $20(10-36.25)$ \\
& $10(3-32.5)$ & $10(5-20)$ & $28.1 \pm 20.4$ \\
Change in VAS score in from baseline mean \pm SD, median (IQR) & & $28(23-33)$ \\
15th minute & $32 \pm 23.7$ & $43.4 \pm 25.8$ & $55.8 \pm 23.4$ \\
& $33(25-39)$ & $43(34-50)$ & $58(50-64)$ \\
30th minute & $63.1 \pm 24.9$ & $67 \pm 20.5$ & \\
& $65(58-72)$ & $67(60-73)$ & $4(4-4)$ \\
Verbal rating score, median (IQR) & & $4(4-4)$ & $3(2-3)$ \\
Baseline & $4(4-4)$ & $2(1-3)$ & $1(1-2)$ \\
15th minute & $2(2-3)$ & $1(1-2)$ & \\
30th minute & $1(1-2)$ & &
\end{tabular}


Table 2 Comparison of reduction in visual analogue scale scores between groups at 15th and 30th minutes

\begin{tabular}{lccc}
\hline Mean differences & Paracetamol versus morphine & Paracetamol versus dexketoprophen & Morphine versus dexketoprophen \\
\hline Reduction at 15th minute, mean $(95 \% \mathrm{Cl})$ & $11.3 \pm 5.2(1$ to 22$)$ & $4 \pm 4.6(-13$ to 5$)$ & $15.3 \pm 4.8(-25$ to 6$)$ \\
Reduction at 30th minute, mean $(95 \% \mathrm{Cl})$ & $3.8 \pm 4.9(-6$ to 14$)$ & $7.4 \pm 5(-18$ to 3$)$ & $11.2 \pm 4.7(2$ to 21$)$ \\
\hline
\end{tabular}

no difference between the two drugs at the 60th minute regarding the decrease in pain and rescue drug, although more side effects with meperidine did occur (10\% vs 55\%). Zippel et al ${ }^{18}$ compared four doses of intaramuscular dexketoprofen daily to intramuscular diclofenac twice daily in acute LBP with outpatient follow-up. They reported no difference between the two drugs at the 6th hour from baseline and similar side effects.

The presented study was the first to investigate the efficacy of paracetamol and dexketoprofen in acute LBP in the ED. Morphine decreased the pain intensity $15 \mathrm{~mm}$ more than dexketoprofen with a lack of statistical significance, and $11 \mathrm{~mm}$ more than paracetamol at the 15 th minute. Although there was no difference between morphine and paracatemol at the 30th minute, morphine decreased the pain $11 \mathrm{~mm}$ more than dexketoprofen with a statistical significance, but a lack of clinical significance. Patients in the morphine group also required less rescue drug but experienced more side effects, both of which occurred at a lack of statistical significance.

\section{Limitations}

This study showed that morphine is not superior to paracetamol and dexketoprofen in relieving acute LBP; however, this does not mean these three drugs are equal. A larger sample size would be needed to test the hypothesis that intravenous morphine, paracetamol and dexketoprofen are equally effective in ceasing acute LBP (an equivalence trial). Although we planned to perform intention-to-treat analysis, and performed this at the 15 th minute analysis, we were not able to gather the VAS scores of four patients at the 30th minute because one patient had an allergic reaction, two patients had hypotension and sedation, and one patient voluntarily left the ED. Besides ceasing the pain effectively, time is important in the ED. Therefore, we measured only the 15 th and 30th minute VAS scores. The delayed effects of these drugs should be the interest of future studies. Instead of measuring the weight of patients, we calculated the dose of morphine according to patient statements.
Figure 2 Box and Whisker plot of change in visual analogue scale from baseline to $30^{\text {th }}$ minute. (a)

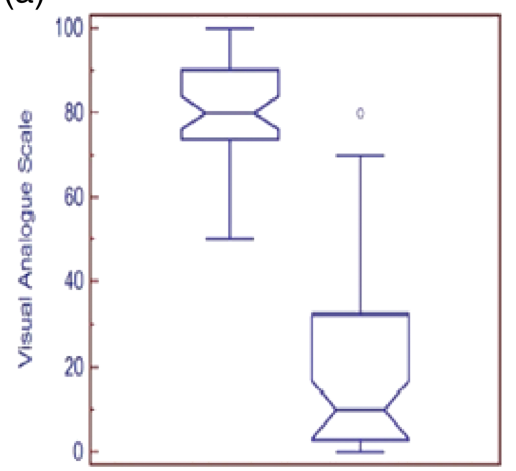

Paracetamol Group (b)

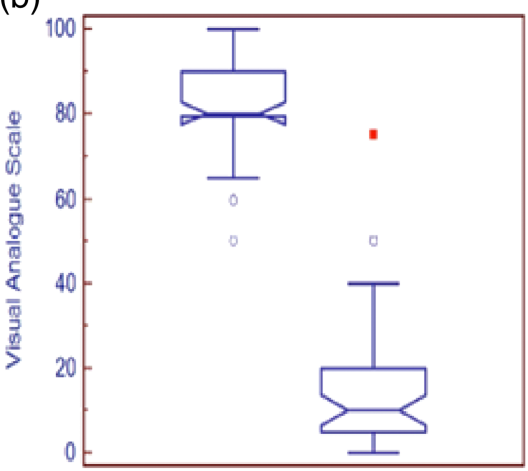




\section{Table 3 Adverse effects}

\begin{tabular}{llll}
\hline Variable & $\begin{array}{l}\text { Paracetamol } \\
\mathbf{n}(\%)\end{array}$ & $\begin{array}{l}\text { Morphine } \\
\mathbf{n}(\%)\end{array}$ & $\begin{array}{l}\text { Dexketoprophen } \\
\mathbf{n}(\%)\end{array}$ \\
\hline $\begin{array}{l}\text { At least one adverse } \\
\text { effect }\end{array}$ & $4(8.7)$ & $7(15.5)$ & $4(8.7)$ \\
$\begin{array}{l}\text { Allergic reaction } \\
\text { (urticaria or itching) }\end{array}$ & 2 & 0 & 0 \\
Vertigo & 0 & 1 & 0 \\
Nausea and vomiting & 2 & 1 & 2 \\
Mild sedation & 0 & 1 & 0 \\
Hypotension & 0 & 1 & 0 \\
Dizziness & 0 & 3 & 0 \\
Dry mouth & 0 & 0 & 2 \\
\hline n; number. & & &
\end{tabular}

\section{CONCLUSION}

We conclude that intravenous paracetamol, dexketoprofen and morphine are not superior to each other for the treatment of mechanical LBP in the ED.

Contributors Contributorship and data collection: MS, HE and EU.; Served as scientific advisors: CE and MS. Statistical study: ME.

Competing interests None.

Patient consent Obtained.

Provenance and peer review Not commissioned; externally peer reviewed.

\section{REFERENCES}

1 Friedman BW, Chilstrom M, Bijur PE, et al. Diagnostic testing and treatment of low back pain in United States emergency departments: a national perspective. Spine (Phila Pa 1976) 2010;35:E1406-11.

2 Craig M, Jeavons $\mathrm{R}$, Probert J, et al. Randomised comparison of intravenous paracetamol and intravenous morphine for acute traumatic limb pain in the emergency department. Emerg Med J 2012;29:37-9.
3 Veenema KR, Leahey N, Schneider S. Ketorolac versus meperidine: ED treatment of severe musculoskeletal low back pain. Am J Emerg Med 2000;18:404-7.

4 Holdgate A, Pollock T. Nonsteroidal anti-inflammatory drugs (NSAIDs) versus opioids for acute renal colic. Cochrane Database Syst Rev 2005;(2):CD004137. Review.

5 Barbanoj MJ, Antonijoan RM, Gich I. Clinical pharmacokinetics of dexketoprofen. Clin Pharmacokinet 2001;40:245-62.

6 Sinatra RS, Jahr JS, Reynolds LW, et al. Efficacy and safety of single and repeated administration of $1 \mathrm{gram}$ intravenous acetaminophen injection (paracetamol) for pain management after major orthopedic surgery. Anesthesiology 2005;102:822-31.

7 Cattabriga I, Pacini D, Lamazza G, et al. Intravenous paracetamol as adjunctive treatment for postoperative pain after cardiac surgery: a double blind randomized controlled trial. Eur J Cardiothorac Surg 2007;32:527-31.

8 Bektas F, Eken C, Karadeniz O, et al. Intravenous paracetamol or morphine for the treatment of renal colic: a randomized, placebo-controlled trial. Ann Emerg Med 2009; 54:568-74.

9 Grissa MH, Claessens YE, Bouida W, et al. Paracetamol vs piroxicam to relieve pain in renal colic. Results of a randomized controlled trial. Am J Emerg Med 2011;29:203-6.

10 Serinken $M$, Eken C, Turkcuer I, et al. Intravenous paracetamol versus morphine for renal colic in the emergency department: a randomized double-blind controlled trial. Emerg Med J 2012;29:902-5.

11 Balagué $F$, Mannion AF, Pellisé $F$, et al. Non-specific low back pain. Lancet 2012;379:482-91.

12 Dagenais S, Tricco AC, Haldeman S. Synthesis of recommendations for the assessment and management of low back pain from recent clinical practice guidelines. Spine J 2010;10:514-29.

13 Chou R, Qaseem A, Snow V, et al. Diagnosis and treatment of low back pain: a joint clinical practice guideline from the American College of Physicians and the American Pain Society. Ann Intern Med 2007;147:478-91.

14 Chou R, Huffman LH. Medications for acute and chronic low back pain: a review of the evidence for an American Pain Society/American College of Physicians clinical practice guideline. Ann Intern Med 2007;147:505-14.

15 Bach SM, Holten KB. Guideline update: what's the best approach to acute low back pain? J Fam Pract 2009;58:E1.

16 Duggan ST, Scott LJ. Intravenous paracetamol (acetaminophen). Drugs 2009;69:101-13.

17 Roelofs PD, Deyo RA, Koes BW, et al. Non-steroidal anti-inflammatory drugs for low back pain. Cochrane Database Syst Rev 2008;(1):CD000396.

18 Zippel H, Wagenitz A. A multicentre, randomised, double-blind study comparing the efficacy and tolerability of intramuscular dexketoprofen versus diclofenac in the symptomatic treatment of acute low back pain. Clin Drug Investig 2007;27:533-43. 